\title{
Aneurysmal Bone Cyst in Cranial Fibrous Dysplasia: A Case Report
}

Wael Elleuch*, Sondes Briki, Fathi Karray, Morched Dhouib and Mohamed Abdelmoula

Department of Oral and Maxillofacial Surgery, La Rabta Hospital Tunis, Tunisia

*Corresponding author: Wael Elleuch, Department of Oral and Maxillofacial Surgery, La Rabta Hospital Tunis, Tunisia, Tel: +21698457942; E-mail: waelelleuch2@gmail.com

Rec date: May 23, 2016; Acc date: Jul 22, 2016; Pub date: Jul 24, 2016

Copyright: $\odot 2016$ Elleuch W. This is an open-access article distributed under the terms of the Creative Commons Attribution License, which permits unrestricted use, distribution, and reproduction in any medium, provided the original author and source are credited.

\begin{abstract}
Acronyms: FD: Fibrous Dysplasia; ABC: Aneurysmal Bone Cyst

Summary: Fibrous dysplasia (FD) of bone is an uncommon skeletal disorder with a broad spectrum of clinical expressions that affects primarily the craniofacial bones. It may be affected by the evolution of lesions over time and by the appearance of superimposed changes, such as aneurysmal bone cysts (ABCs).

We describe an unusual case of a cranial $A B C$ accuring after long evolution of fronto-parietal FD in 16 years old girl. She was operated successfully with total removing of the ABC. After of follow up of 6 months, she was symptom free and CT scan revealed no evidence of recurrence.
\end{abstract}

Keywords: Fibrous dysplasia; Aneurysmal bone cysts

\section{Introduction}

FD is infrequent sequeletal disorder that affects mostly cranio-facial bones [1]. The occurrence of a concomitant FD and ABC in the cranial bones is extremely rare. We report a case of fronto-parietal FD with an $\mathrm{ABC}$ of a 16-year-old young woman.

\section{Case Report}

A 16 years old woman, with a history of stabilized cranial FD, was admitted to our department for a quickly growing painless left parietal mass almost five years after diagnosis. She noticed that the lesion expanded in the four last months.

Physical exam showed a tender mass in the left parietal region approximately $(6 \mathrm{~cm} / 4 \mathrm{~cm})$. We find no changes in the overlying skin (Figure 1).

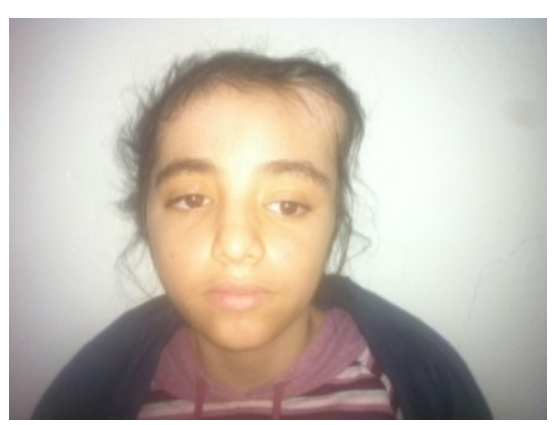

Figure 1: Physical examination showing left parietal mass.

\section{Neurological examination}

CT scan three-dimensional reconstruction revealed a unilocular cystic lesion of $6 \mathrm{~cm}$ diameter in the parietal bone with osteolysis of the outer and inner skull table. The MRI showed that the cyst had "fluidfluid levels" which strongly suggested ABC.

\section{Surgical Procedure}

Patient was operated with parietal approach. The cystic tumor was well defined with no scalp adhesion, it was highly vascular mass and excessive bleeding occurred during operation. In multiple areas, the cyst wall was tightly adherent to the parietal dura. The calvarias adjacent to the tumor had abnormal texture and all bony attachment to the cyst was drilled down as necessary.

Total removal of the cyst was achieved. Patient tolerated the operation well and without complication. Simultaneous reconstruction using artificial bone graft was performed.

Pathologic examination revealed that the tumor was composed of cystic fibrous wall including lymphocytes, histiocytes, plasma cells and neutrophils. There were also giant osteoclast cells, trabecular bone and striated muscle cells.

The follow up after 6 months showed no sign of recurrence and the CT scan of the head showed a good osteo-integration of the graft without radiological sign of recurrence (Figure 2).

\section{Discussion}

ABC was first described by Jaffe and Lishtenstein in 1942 [2]. It is a rare benign vascular lesion of the bone but locally aggressive. It most involves the long tubular bones and spine [3] and cranial location is about 3 to $6 \%$. It could attend a giant mass [4].

It may occur as primary lesion or a secondary to other lesion: osteoblastoma [5], ossifying fibroma [6], chondroblastoma [7]. 
Only 14 cases of calverious FD with secondary $\mathrm{ABC}$ have been reported [8].

$\mathrm{ABC}$ may be primary or secondary. The exact cause of $\mathrm{ABC}$ is uncertain. The development of focal dynamic changes with secondary venous hypertension may cause a slow expansion of the cortex. Many others propose the hypothesis of the existence of a basic underlying arteriovenous anomaly that results in dilated vascular spaces. Other authors proposed that genetic or chromosomal changes are involved in ABCs [3-10].

Plain radiographs of aneurysmal bone cysts in the skull typically reveal osseous expansion with involvement of the inner and outer tables and intracranial extension. On CT scans, ABC appears as welldemarcated, multi-loculated, osteolytic lesions. Fluid-fluid levels are sometimes apparent when the patient is motionless for a few minutes. MRI easily depicts additional information about the internal septa; it completely delineates the margin of the lesion as a rim of low signal intensity, and demonstrates fluid-fluid levels. MRI helps in further identifying hemorrhage [11].

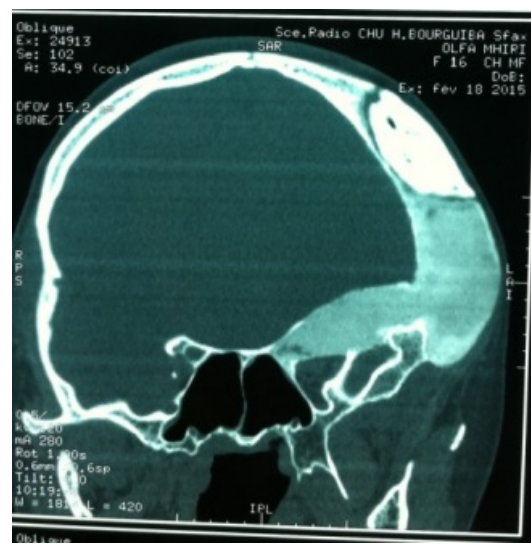

Figure 2: Post-operative CT-Scan: good osteo-integration of the graft with no sign of recurrence.

Complete surgical excision is the treatment of choice and may a satisfying outcome of the almost all surgeon. It can be facilitated by preoperative embolization [5].

Other therapeutic modalities are medical management, such as interferon a-2a and radiation therapy, or calcitonin injection in case of unresectable tumor [12-14].

\section{Conclusion}

FD must be follow up by clinical and radiologic explorations to detect compressive symptoms or secondary lesion such as AC. Rapid enlargement of FD lesions is suggestive of cystic degeneration.
Early diagnosis and prompt surgical treatment usually lead to good outcome.

\section{References}

1. Hanifi B, Sami KS, Yasar C, Cengiz C, Ercan A, et al. (2013) Craniofacial fibrous dysplasia. Clinical Imaging 37: 1109-1115.

2. Jaffe HL, Lichtenstien L (1942) Solitary unicameral bone cyst with emphasis on the roentgen picture, the pathologic appearance and the pathogenesis. Arch Surg 44: 1004-1025.

3. Aucourt J, Aubert S, Lesage A, Lefebvre G, Renaud A, et al. (2013) Tumeurs osseuses. Imagerie musculosquelettique - Pathologies générales 461-514.

4. Mazlout O (2005) Kyste osseux anévrismal de l’ethmoïde. J Radiol 86: 948-950.

5. Han X, Dong Y, Sun K, Lu Y (2008) A huge occipital osteoblastoma accompanied with aneurysmal bone cyst in the posterior cranial fossa. Clinical Neurology and Neurosurgery 110: 282-285.

6. Urs AB, Augustine J, Arora S, Kumar P (2013) Rare pediatric presentation of aneurysmal bone cyst with trabecular juvenile ossifying fibroma and ossifying fibroma. Int J Pediatr Otorhinolaryngol 77: 576-580.

7. Liu Y, Wang H, You M, Yang Z, Miao J, et al. (2013) ossifying fibroma and ossifying fibroma. International Journal of Pediatric Otorhinolaryngology 77: 576-580.

8. Stapleton CJ, Walcott BP, Linskey KR, Kahle KT, Nahed BV, et al. (2011) Temporal bone chondroblastoma with secondary aneurysmal bone cyst presenting as an intracranial mass with clinical seizure activity. Case Reports/Journal of Clinical Neuroscience 18: 857-860.

9. Terkaw AS, Al-Qahtani KH, Baksh E, Soualmi L, Mohamed AE, et al. (2011) Fibrous dysplasia and aneurysmal bone cyst of the skull base presenting with blindness: a report of a rare locally aggressive example. Head \& Neck Oncology 3: 15.

10. Wang J, Zhang M, Zhao X (2015) Aneurysmal bone cyst of the orbit. Chin Med J (Engl) 128: 562-563.

11. Ciccone MM, Galeandro AI, Scicchitano P, Zito A, Gesualdo M et al. (2012) Multigate quality Doppler profiles and morphological/ hemodynamic alterations in multiple sclerosis patients. Curr Neurovasc Res 9: 120-127.

12. Lin SP, Fang YC, Chu DC, Chang YC, Hsu CI (2007) Characteristics of cranial aneurysmal bone. J Formos Med Assoc. Mar 106: 255-259.

13. [No authors listed] Cyst on computed tomography and magnetic resonance imaging. J Formos Med Assoc 1: 3.

14. Khaldi M, Ben Hamouda K, Moussa M, Megdiche H, Boubaker A, et al. (2006) Kyste anévrysmal de la base du crâne. À propos d'un cas traité par exérèse partielle et injection de calcitonine. Neurochirurgie 52: 57-62. 